\title{
Intraoperative ultrasonography for presumed brain metastases: a case series study
}

\author{
Uso de ultrassonografia intraoperatória para metástases cerebrais presumidas: estudo \\ de uma série de casos
}

\author{
Helder Picarelli', Marcelo de Lima Oliveira², Edson Bor-Seng-Shu², Eduardo Santamaria Carvalhal Ribas²,
} Alexandre Maria Santos ${ }^{1}$, Manoel Jacobsen Teixeira²

\begin{abstract}
Brain metastases (BM) are one of the most common intracranial tumors and surgical treatment can improve both the functional outcomes and patient survival, particularly when systemic disease is controlled. Image-guided BM resection using intraoperative exams, such as intraoperative ultrasound (IOUS), can lead to better surgical results. Methods: To evaluate the use of IOUS for BM resection, 20 consecutives patients were operated using IOUS to locate tumors, identify their anatomical relationships and surgical cavity after resection. Technical difficulties, complications, recurrence and survival rates were noted. Results: IOUS proved effective for locating, determining borders and defining the anatomical relationships of BM, as well as to identify incomplete tumor resection. No complications related to IOUS were seen. Conclusion: IOUS is a practical supporting method for the resection of BM, but further studies comparing this method with other intraoperative exams are needed to evaluate its actual contribution and reliability.
\end{abstract}

Key words: intraoperative ultrasound, brain metastases, neurosurgery.

\section{RESUMO}

As metástases cerebrais (MC) são os tumores intracranianos mais frequentes e seu tratamento cirúrgico pode melhorar a sobrevida e a funcionalidade do paciente, especialmente quando a doença sistêmica está controlada. A ressecção das MC guiada por imagens de exames intraoperatórios, como ultrassom intraoperatório (USIO), pode levar a melhores resultados cirúrgicos. Métodos: Avaliar o uso do USIO nas ressecções de MC de 20 pacientes para localizar os tumores, avaliar suas relações anatômicas e a cavidade cirúrgica após o procedimento. As dificuldades técnicas, complicações, recorrência e taxa de sobrevivência foram anotadas em cada caso. Resultados: USIO foi eficaz para localizar, delinear e definir as relações anatômicas das MC, assim como a ocorrência de ressecção incompleta. Não foram encontradas complicações relacionadas ao uso do USIO. Conclusão: USIO é um método auxiliar prático para as ressecções de MC, porém outros estudos ainda se fazem necessários para avaliar sua real contribuição nesses procedimentos.

Palavras-Chave: ultrassom intraoperatório, metástases cerebrais, neurocirurgia.

Brain metastases (BM) represent more than $50 \%$ of intracranial tumors in the adult population and have shown an increasing incidence over recent decades ${ }^{1,2}$. Around 170,000 patients per year are diagnosed with BM in the United States of America. In addition, $10 \%$ to $40 \%$ of oncologic patients develop BM in the course of the disease ${ }^{1-8}$. The factors associated with this increasing incidence include advances in neuroimaging techniques, easier access to health care systems, and increased survival of cancer patients. The best strategy for treating BM remains controversial, but the management includes radiotherapy, stereotactic radiosurgery and surgical resection. Patients are typically treated according to age, functional performance, neurological status, type of cancer, number and localization of BM, radiosensitivity and chemosensitivity of the tumors, and systemic control of the primary cancer $^{5-8}$. Local control of BM can restore neurological functional status and increase survival of patients that may die due to extracranial progression of the disease $e^{9-12}$. Some trials suggest that neurosurgical resection is a good option, presenting low recurrence rates especially when followed by radiotherapy ${ }^{6-8,11,12}$. BM resection can rapidly decrease the mass effect and surrounding edema, improve symptoms and quality of life, control epileptic seizures and provide tissue for histological analysis and diagnosis of suspected lesions ${ }^{6-8}$. In addition, resection of multiple BM can also bring positive outcomes if systemic cancer is controlled ${ }^{13-15}$. The objective

1Division of Neurological Surgery, Instituto do Câncer do Estado de São Paulo "Octavio Frias de Oliveira”, São Paulo SP, Brazil;

${ }^{2}$ Division of Neurological Surgery, Hospital das Clínicas da Faculdade de Medicina da Universidade de São Paulo, São Paulo SP, Brazil.

Correspondence: Helder Picarelli; Rua Itacolomi 222 / conj. 5;01239-020 São Paulo SP - Brasil, e-mail: helderpicarelli@icesp.org.br / helderpicarelli@ig.com.br Conflict of interest: There is no conflict of interest to declare.

Received 21 December 2012; Received in final form 08 June 2012; Accepted 15 June 2012 
of surgical treatment is to achieve complete tumor resection with minimal damage to adjacent structures. The use of intraoperative image guidance, such as neuronavigation, magnetic resonance imaging (MRI) or ultrasonography (US), allows a more accurate detection of $\mathrm{BM}$ and reveals their anatomical relationships, possibly leading to better surgical results $^{16-19}$. The present study reports a series of twenty patients with BM in whom intraoperative ultrasound, henceforth referred to as IOUS, was used to locate and guide tumor resection, as well as to prevent vascular injuries. After the tumor resection, IOUS was performed to identify residual tumor cells, blood clots and foreign bodies in the surgical bed.

The aims of this study were to evaluate the effectiveness of IOUS in locating and accurately defining tumors and to disclose relationships with adjacent tissues. Additionally, the use of IOUS to identify residual tumors, clots and foreign bodies in the surgical cavity immediately after tumor resection was also assessed.

\section{METHODS}

Twenty consecutive patients with medical history and/ or lesions in MRI consistent with BM were treated by surgical resection aided by IOUS and followed up prospectively for one year. The decision to perform surgical resection was taken by a neuro-oncology multidisciplinary group from our institution, according to a protocol approved by the local Ethics Committee. All patients were given phenytoin (300 mg/d), dexamethasone (16 mg/d) and a prophylactic antibiotic (cefuroxime) before and during the procedure. The patient position during the operation and craniotomy was decided according to the tumor location shown by radiological exams, MRI (Fig 1), and the surgery was performed using classical neurosurgical and stereotactic techniques. Doppler ultrasonography was performed immediately after the opening of the dura mater and once again at the end of the surgery using a high-resolution system (MicroMax" model, Sonosite, Bothel, WA) with broadband phased array transducers. The transducers (6-13 and 4-8 MHz) were protected by sterile plastic covers (Fig 1) and saline irrigation was used to improve images. IOUS was first used to determine the tumor location and to evaluate its volume, as well as to define its borders and relationships with adjacent tissues, and the best surgical route to reach the BM (Figs 1-5). After surgery, IOUS was used to identify any residual tumor cells, hematomas or foreign bodies (Fig 4A). Technical difficulties, duration of the surgery, time required to locate the lesions by IOUS, and surgical complications during or after the surgery were all noted.

The accuracy of IOUS for locating tumors was compared to that of stereotactic localization by Aimsystem ${ }^{\circledR}$ Stereotactic System $\left(\right.$ Micromar $\left.^{\circledR}\right)$. The lesions' volume estimated by IOUS were compared to the estimates based on the preoperative MRI using the formula $\mathrm{V}=\pi / 6 \mathrm{xAxBxC}$ (where $\mathrm{A}, \mathrm{C}$ and
D correspond to the largest tumor diameter on sagittal, coronal and axial views). The presence of residual tumor cells in the surgical cavity was assessed by IOUS after the resection; the imaging was later on compared to the brain CT-scan

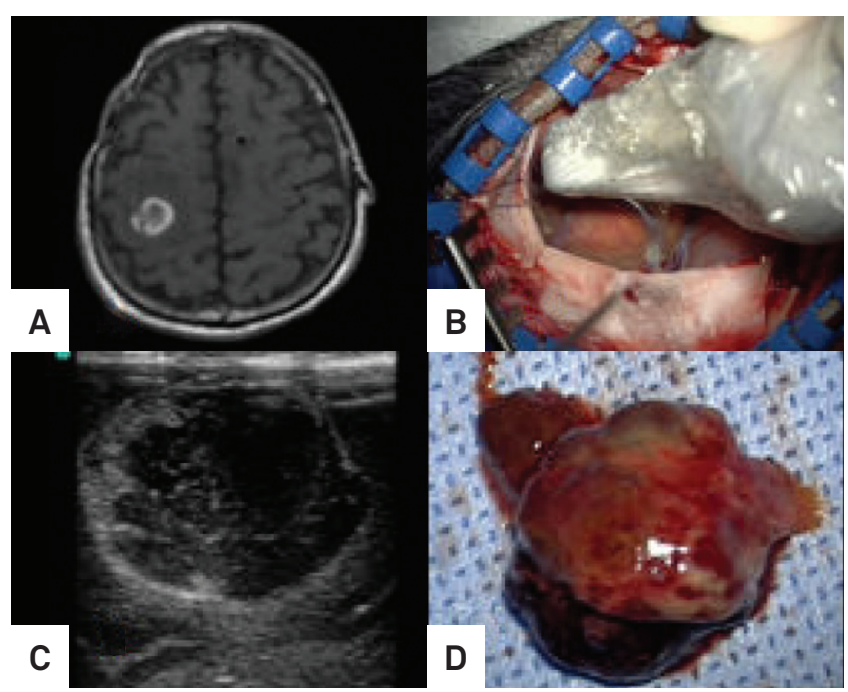

Fig 1. Case 2: Cavernoma. (A) Magnetic Resonance Images, (B) Intraoperative ultrasound, (C) IOUS Images of subcortical and hypoechoic tumor, (D) Tumor was resected em bloc.

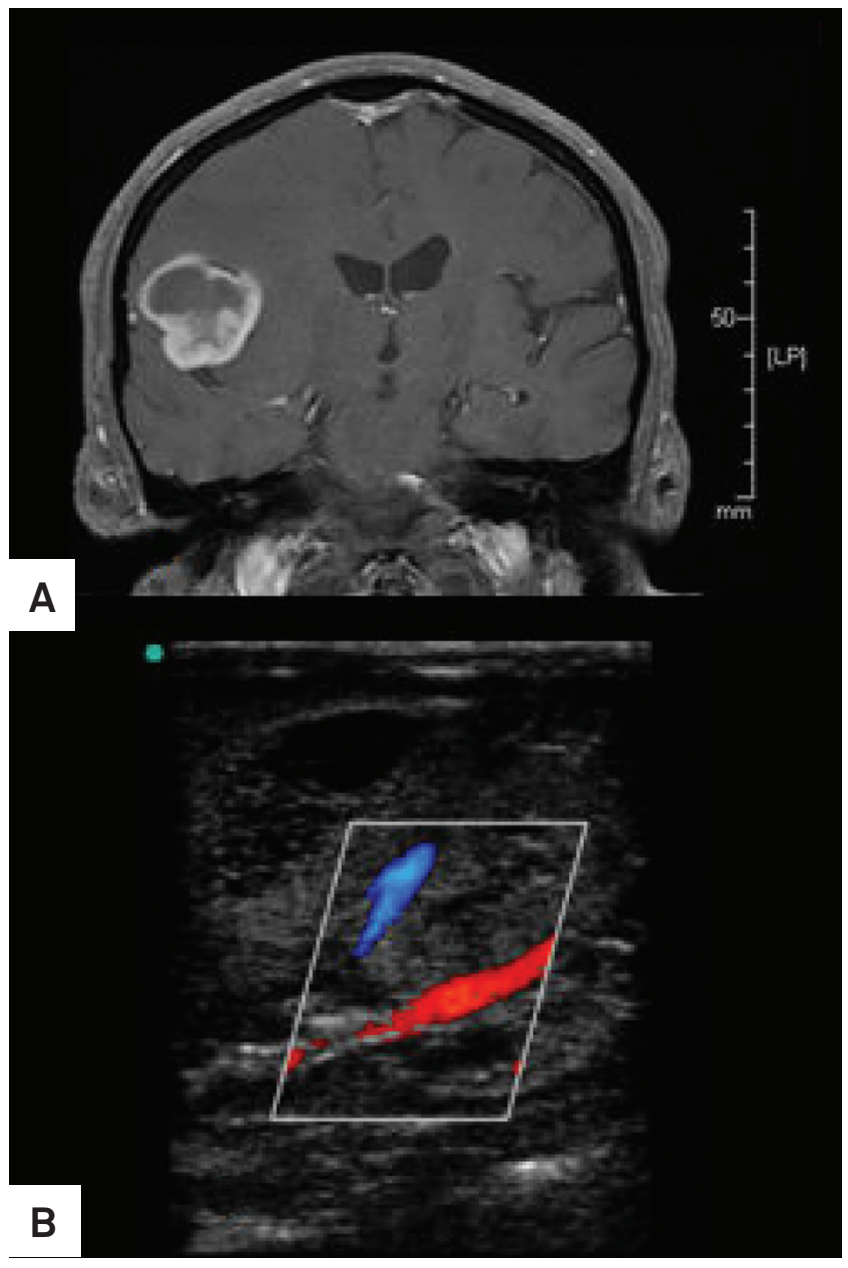

Fig 2. Case 10: Glioblastoma Multiforme. (A) Contrast enhanced T1 MRI image; (B) IOUS showing middle cerebral artery branch within tumor. 


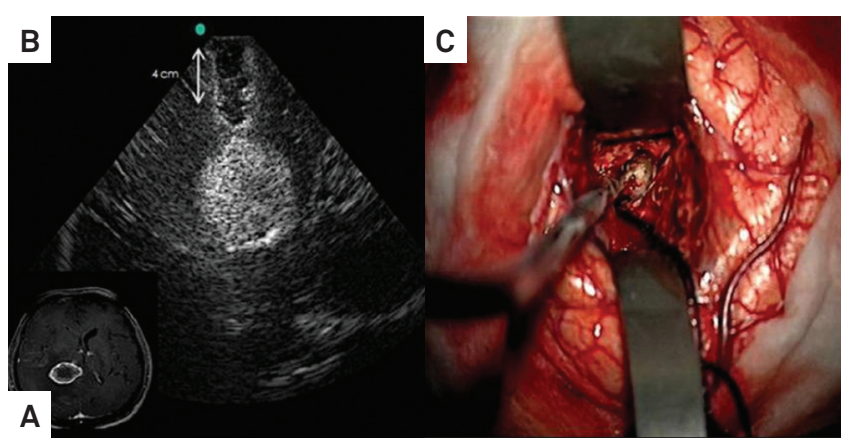

Fig 3. Case 5: Thalamic Brain Metastasis of colon adenocarcinoma. (A) Contrast enhanced T1 MRI image, (B) IOUS showing corticectomy and optimal route to reach tumor, (C) Intraoperative view.

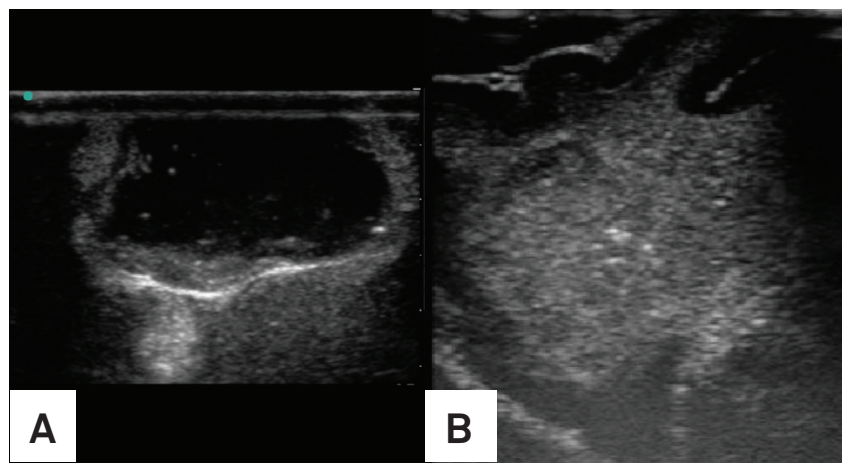

Fig 4. Brain metastasis of breast cancer. (A) IOUS image after the lesion resection discloses another small tumor below the surgical cavity, not seen under the microscope.

images, performed in all cases within 24 hours postoperatively. Differences between tumor volumes calculated using IOUS compared to preoperative MRI greater than or equal to $5 \%$ were considered discordant predicted volumes (p-value). Contrast-enhancing brain lesions on the postoperative CTscan were regarded as probable residual tumor cells and considered discordant if IOUS did not detect the same finding. The suspected areas identified by IOUS were biopsied and sent to the laboratory for anatomopathological examination. All patients received the same radiotherapy irradiation dose to the surgical site given within the first five weeks of surgery.

\section{RESULTS}

Patients' mean age was 53.4 years (26-76 years), twelve of them were males (60\%), and three (15\%) had no previous oncological history. Twenty-three BM were operated in the study (Table 1). Histological analysis confirmed BM in $85 \%$ of the patients. Two of them were diagnosed with glioblastoma multiforme and one with cavernoma (Fig 1 and Table 2). In all cases, IOUS indicated the tumor localization in the first minute of the exam, and the results were in agreement with stereotactic localization. In all cases, ultrasonographic characterization of

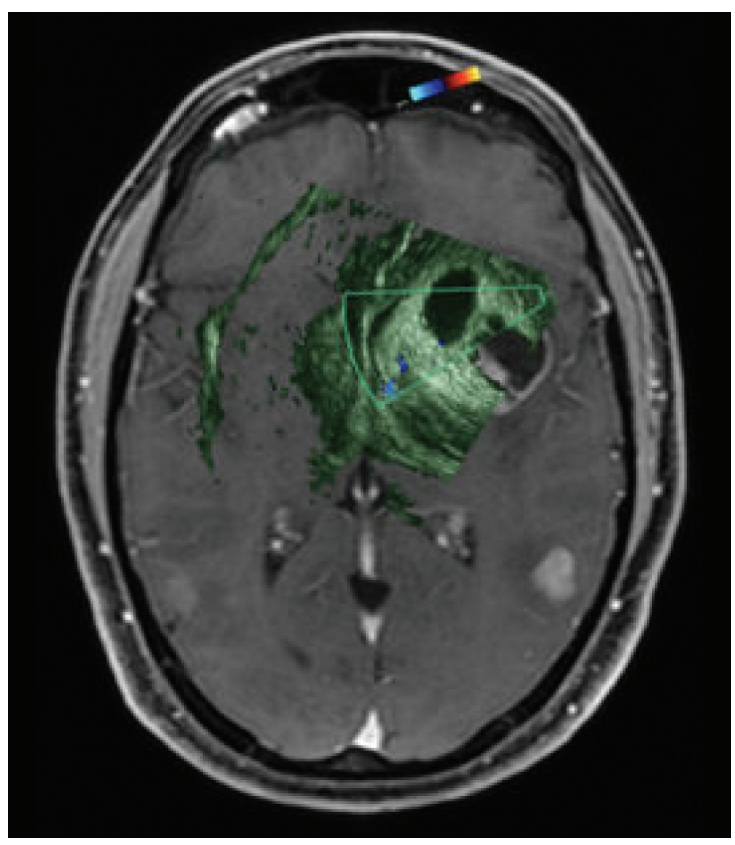

Fig 5. Case 4: Brain metastasis of melanoma. Merged IOUS and MRI images: the IOUS oriented the corticectomy and the best route to approach the tumor through the insula. Images clearly show ventricles, midline shift, tumor and relationships with middle artery branches. This patient had a good neurological recovery immediately after the surgery with no motor deficit and he's submitted to radiotherapy. Two hundread and thirty days later he died of gastrointestinal bleeding secondary to bowel metastases and meningeal carcinomatosis. There was not local recurrence.

the lesions was in agreement with the preoperative MRI findings in terms of tumor borders and anatomical relationships to ventricular and vascular structures. The volume of the lesion was calculated based on intraoperative US images in five patients, and a significant correspondence to the volume calculated from the preoperative MRI was observed in all cases. Six lesions (26.1\%) were superficial, at the cortex, being identified by direct visualization; IOUS was then used to determine the echographic characteristics and anatomical relationships, and to search for residual tumor cells after resection. Seventeen lesions were subcortical, and intraoperative US was used in these cases to guide the surgeon in electing the best route to reach the lesion (Figs 4 and 5).

In eleven cases (55\%), IOUS identified suspected areas of residual tumor cells at the surgical bed, eight of which $(72.7 \%)$ were later confirmed by anatomopathological examination (Fig 4A). The three remaining suspected lesions were diagnosed as gliosis, necrosis and thermal lesion. No contrast-enhancing lesions supposedly missed by IOUS were identified in the postoperative CT-scan.

Doppler color flow imaging mode revealed important relations between the vascular structures and the tumor in five cases (25\%), but accidental vascular injuries were not found. In four cases (20\%), the surgical strategy was modified based on 
Table 1. Patients and data.

\begin{tabular}{|c|c|c|c|c|c|c|c|c|}
\hline Case & $\begin{array}{c}\text { Age } \\
\text { (years) }\end{array}$ & Oncological history & $\begin{array}{l}N^{\circ} \text { of Lesions/ } \\
\text { volume }(\operatorname{cc} 3)^{*}\end{array}$ & Localization & ASA & ECOG & SIR & KPS \\
\hline 1 & 42 & $\begin{array}{c}\text { Breast Invasive ductal } \\
\text { carcinoma }\end{array}$ & $2 / 6.56$ & C-SC, occipital & $\|$ & 1 & 6 & 80 \\
\hline 2 & 57 & Lymphoma & $1 / 3.81$ & precentral gyrus & III & 4 & 7 & 40 \\
\hline 3 & 26 & Osteosarcoma & $1 / 77.71$ & C-SC-P, frontal lobe & III & 1 & 6 & 80 \\
\hline 4 & 45 & Melanoma & $1 / 17.08$ & $\mathrm{D}$, insula & III & 1 & 4 & 90 \\
\hline 5 & 61 & Colon adenocarcinoma & $1 / 15.5$ & $\mathrm{D}$, thalamus & $\|$ & 2 & 3 & 80 \\
\hline 6 & 41 & Colon adenocarcinoma & $1 / 13.13$ & D, parieto-occipital & $\|$ & 1 & 6 & 70 \\
\hline 7 & 76 & $x$ & $1 / 14.97$ & C-SC, parieto-occipital & III & 2 & 2 & 40 \\
\hline 8 & 70 & $x$ & $1 / 7.24$ & C-SC, parietal & III & 3 & 3 & 50 \\
\hline 9 & 52 & Clear cell renal carcinoma & $3 / 1.98$ & C-SC, occipital & III & 3 & 3 & 50 \\
\hline 10 & 70 & Prostate adenocarcinoma & $1 / 22.08$ & D, frontal & III & 1 & 6 & 90 \\
\hline 11 & 34 & Melanoma & $1 / 3.04$ & C-SC, frontal & । & 1 & 7 & 90 \\
\hline 12 & 49 & $x$ & $1 / 31.34$ & C-SC-D, parieto-occipito-temporal & $\|$ & 1 & 7 & 80 \\
\hline 13 & 67 & $\begin{array}{c}\text { Breast Invasive ductal } \\
\text { carcinoma }\end{array}$ & $1 / 8.05$ & $\mathrm{D}$, cerebellum & $\|$ & 1 & 5 & 90 \\
\hline 14 & 65 & Lung adenocarcinoma & $1 / 2.84$ & C, frontal & ॥ & 3 & 3 & 40 \\
\hline 15 & 64 & $\begin{array}{c}\text { Breast Invasive ductal } \\
\text { carcinoma }\end{array}$ & $1 / 9.97$ & C-SC, frontal & III & 2 & 6 & 80 \\
\hline 16 & 26 & Melanoma & $1 / 12.23$ & D, temporal & $\|$ & 1 & 7 & 90 \\
\hline 17 & 72 & Urinary bladder carcinoma & $1 / 56.16$ & C-SC, frontal & III & 4 & 2 & 30 \\
\hline 18 & 63 & Lung adenocarcinoma & $1 / 23.47$ & D, parieto-occipital & III & 3 & 2 & 50 \\
\hline 19 & 42 & $\begin{array}{c}\text { Breast Invasive ductal } \\
\text { carcinoma }\end{array}$ & $1 / 3.78$ & SC, frontal & III & 1 & 6 & 90 \\
\hline 20 & 47 & Melanoma & $1 / 18.14$ & $\mathrm{D}$, cerebellum & $\|$ & 1 & 6 & 70 \\
\hline
\end{tabular}

C: cortical, SC: subcortical, D: deep, ASA: American Society of Anesthesiologists classification, ECOG: Eastern Cooperative Oncology Group performance status, SIR: Score Index for Radiosurgery of brain metastases, KPS: Karnofsky Performance Scale.

*Volume: $\pi / 6 \times A \times B \times C$, where A, B and C correspond to the lesion's largest diameter on axial, coronal and sagittal MRI images.

Table 2. Surgical findings, IOUS image characteristics, and postoperative evolution.

\begin{tabular}{|c|c|c|c|c|c|}
\hline Case & $\begin{array}{l}\text { Anatomopathological } \\
\text { diagnosis }\end{array}$ & IOUS findings & $\begin{array}{l}\text { Complete R } \\
\text { (IOUS) }\end{array}$ & $\begin{array}{l}\text { Complete R } \\
\text { (CT-scan) }\end{array}$ & Recurrence \\
\hline 1 & Metastatic carcinoma & Solid and hyperechoic lesion, WD, PE, WOVR & Yes & Yes & No \\
\hline 2 & Cavernoma & Cystic and hypoechoic lesion, WD, small PE, WORV & Yes & Yes & No \\
\hline 3 & Osteosarcoma & Cystic and hypoechoic lesion, WD, small PE, WORV, RT & Yes & Yes & No \\
\hline 4 & Melanoma & Solid-cystic and heterogenous lesion, WD, MCA relation, RT & No & No & Yes \\
\hline 5 & Colon Adenocarcinoma & Solid and hyperechoic lesion, WD, PE, WOVR, LV relation, RT & Yes & Yes & Yes \\
\hline 6 & Colon Adenocarcinoma & Solid and hyperechoic lesion, WD, PE, WOVR, LV relation, RT & Yes & Yes & No \\
\hline 7 & Lung carcinoma & Solid-cystic and heterogenous lesion, WD, torcula relation, RT & Yes & Yes & No \\
\hline 8 & Lung carcinoma & $\begin{array}{l}\text { Solid-cystic and predominately hyperechoic lesion, } \\
\text { WD, WOVR, RT }\end{array}$ & Yes & Yes & No \\
\hline 9 & $\begin{array}{l}\text { Urinary bladder } \\
\text { carcinoma }\end{array}$ & Solid and hyperechoic lesion, WD, PE, WOVR, RT & Yes & Yes & No \\
\hline 10 & Glioblastoma multiforme & Heterogenous lesions, WD, MCA relation, RT & Yes & Yes & No \\
\hline 11 & Melanoma & Solid-cystic and hyperechoic lesion, WOVR & Yes & Yes & No \\
\hline 12 & Glioblastoma multiforme & Solid and heterogenous lesion, WD, WOVR & No & No & Yes \\
\hline 13 & Breast IDC & Solid and hyperechoic lesion, WD, WOVR, RT & Yes & Yes & No \\
\hline 14 & Lung adenocarcinoma & $\begin{array}{l}\text { Cystic and hypoechoic lesion with hyperechoic nodule, } \\
\text { WD, WORV, RT }\end{array}$ & Yes & Yes & No \\
\hline 15 & Breast IDC & $\begin{array}{c}\text { Solid lesion with central cystic area, predominantly } \\
\text { hyperechoic, WD, WOVR, RT }\end{array}$ & Yes & Yes & No \\
\hline 16 & Melanoma & Solid and hyperchoic lesion, WD, WOVR & Yes & Yes & Yes \\
\hline 17 & $\begin{array}{l}\text { Urinary bladder } \\
\text { carcinoma }\end{array}$ & Solid and hyperchoic lesion, WD, WOVR & Yes & Yes & No \\
\hline 18 & Lung adenocarcinoma & Cystic and hypoechoic lesion, WD, small PE, WORV & Yes & Yes & No \\
\hline 19 & Breast IDC & Cystic and hypoechoic lesion, WD, WORV & Yes & Yes & No \\
\hline 20 & Melanoma & Cystic and hyperechoic lesion, WD, WORV & Yes & Yes & No \\
\hline
\end{tabular}

PE: perilesional edema, WD: well-delimited, WOVR: without important vascular relations, MCA: middle cerebral artery, LV: lateral ventricle, R: resection, IOUS: intraoperative ultrasound, RT: residual tumor, IDC: breast invasive ductal carcinoma. 
IOUS findings, which revealed an alternative route for the neurosurgeon to reach the lesion and perform the resection (Fig 4). Mean total operation time for a single lesion was 289 minutes and total usage of IOUS never exceeded thirty minutes.

There were no complications related to the surgical procedure per se, such as neurological worsening, wound infections, meningitis, abscess, contusions or hematomas. Patient survival time ranged from fifteen days (death related to sepsis and central venous access infection) to 365 days (maximum follow-up time). Functional performance improved after surgery in thirteen patients (65\%), and was unchanged in six of them. The most relevant surgical and follow-up findings are shown in Table 2.

Survival rates in the first, second and third months were 95\%, 95\% and 80\%, respectively. Mean follow-up time was 180 days (15 to 365 days), and three patients presented with local tumor recurrence after BM resection. All recurrences were related to meningeal carcinomatosis (2 patients with melanoma and 1 patient with colon adenocarcinoma) (Fig 3), and these patients died during follow-up.

\section{DISCUSSION}

Brain metastases are more common than primary brain cancer and there is debate over the best treatment protocol. Well-designed studies conducted with patients with single $\mathrm{BM}$, good functional performance, and controlled systemic cancer suggest that neurosurgery is an effective option for local disease control ${ }^{14,15}$. BM happens by expansion and can reach a significant volume, increasing intracranial pressure and promoting inflammation in adjacent tissues and brain vasogenic edema. The complete resection of BM can resolve some of these processes, restoring neurological functions and solving symptoms. Additionally, surgery allows confirmation of the histological diagnosis of the tumor. In our series, BM was confirmed in $85 \%$ of the patients, which enabled their referral, as well as the $15 \%$ non-confirmed cases, to appropriate treatment. Although surgery are very beneficial for patients, the decision should always be made by weighing up the benefits and risks. The surgical morbidity and mortality associated to the procedure are estimated to be less than 3 and 5\%, respectively. The most common complications are neurological worsening, wound infections, intracranial hematomas, deep venous thrombosis, pulmonary embolism and pneumonia.

The extension of tumor resection is an important factor when it comes to decreasing the local tumor progression rate and increasing patient survival. Complete tumor resection is possible provided that the lesion borders are well defined, the tumor is removed en bloc, and potential residual cells are recognized during surgery. Intraoperative radiological exams such as MRI or IOUS may promptly identify lesion borders, anatomical relationships and residual tumor cells with high sensitivity, leading to more complete and safe tumor removal ${ }^{16-19}$. The choice of the method also depends on their availability and on the neurosurgeon's personal experience. Intraoperative MRI provides high-quality images, but is still an expensive option that is rarely available in Brazil. The technique also requires complex infrastructure, and image acquisition time is longer. Lower cost, more practical usage, ability to repeat the exam several times and faster image acquisition are some of the characteristics that make IOUS a more attractive method of choice. All lesions in our series were located in less than one minute using this method, and their size, shape, borders, anatomical relations, as well as identification of necrosis, edema and calcifications were determined in most cases and proved concordant with preoperative exam findings. IOUS also indicated where it was best to open the dura-mater, the direction and relationships of each sulcus with the tumor, the optimal point to perform the corticectomy, and the best route to approach the tumor. The use of Doppler color flow helped identify important vascular structures, preventing possible injuries.

In this study, all tumors were promptly located by IOUS, irrespective of their location. Solid and hypercellular lesions appeared as hyperechoic, homogenous and well-defined images. Hemorrhagic areas and necrosis, detected within some lesions, appeared as hypoechoic images. Small calcifications were not identified by IOUS, but large calcifications were indirectly detected by its acoustic shadow. Cystic lesions were seen as hypoechoic images. Cotton, Surgical and organized hematomas were identified as hyperechoic images, thus enabling later removal. Before tumor resection, we found no difficulties in differentiating the tumor from normal brain tissue. However, it was difficult to differentiate residual tumor cells, gliosis and contusions after resection. Our data suggest that IOUS has high sensitivity but low specificity when used for this purpose. At the end of the procedure, the surgical cavity was filled with $0.9 \%$ saline solution and appeared as a hypoechoic area surrounded by normal brain tissue (Fig 4A). The extension of tumor removal using postoperative MRI (gold-standard) was not evaluated in the present investigation and future studies are needed to compare both methods.

IOUS was used with 6-13 MHz and 4-8 MHz transducers. Better image quality was achieved with the $6-13 \mathrm{MHz}$ transducer, but allowed only superficial (up to $4 \mathrm{~cm}$ from the cortex) lesions to be visualized. Deeper $(2.5$ to $6 \mathrm{~cm}$ from the cortex) lesions were better visualized using the 4-8 MHz transducer. Volume calculation was possible if lesions were small and if their axis could be seen in one single image. Because of the small contact area of the transducer to the brain, the volume was measurable only in only 5 cases (25\%). Dislocation of cerebral structures, a phenomenon known as "brain shift" that occurs during the procedure and interferes with the correct localization of surgical targets when based on preoperative radiological exams, did not affect the accuracy of IOUS ${ }^{18,19}$. 
Incorrect patient positioning or craniotomy procedures, a poor quality IOUS device and little experience of the surgeon with the method can decrease the effectiveness of the exam. However, the skill needed to use this harmless and effective intraoperative guidance tool can be easily acquired with a little dedication. Recent studies have demonstrated that threedimensional IOUS images can be used in conjunction with other intraoperative guidance methods, but further studies are needed to evaluate their advantages.
In conclusion, IOUS constitute a practical, accurate, fast and safe method for guiding BM resections. Tumor lesion identification was made independently of their location or histology. Surgical procedures were oriented by IOUS, which indicated the optimal route to approach the lesions, as well as important anatomical relationships, and residual tumor cells. There was no significant increase in the total surgery time or in complications related to this method. We recommend that all neurosurgeons striving for safer and accurate procedures undergo IOUS training.

\section{References}

1. Landis SH, Murray T, Bolden S, et al. Cancer statistics, 1999. CA Cancer J Clin 1999;49:8-31.

2. Patchell RA, Posner JB. Neurologic complications of systemic cancer. Neurol Clin 1985;3:729-750

3. Klos KJ, O’Neill BP. Brain metastases. Neurologist 2004;10:31-46.

4. Norden AD, Wen P, Kesari S. Brain Metastases. Curr Opin Neurol 2005;18:654-661.

5. Nguyen T, Abrey LE. Brain metastases: old problem, new strategies. Hematol Oncol ClinNorth Am 2007;21:369-388.

6. Richards GM, Khuntia D, Mehta MP. Therapeutic management of metastatic brain tumors. Crit Rev Oncol Hematol 2007;61:70-78.

7. Posner JB, Chernik NL. Intracranial metastases from systemic cancer. Adv Neurol 1978;19:579-592.

8. Posner JB. Management of brain metastases. Rev Neurol 1992;148:477-482.

9. Delattre JY, Krol G, Thaler HT, et al. Distribution of brain metastases. Arch Neurol 1998;45:741-744.

10. Chao ST, Barnett GH, Liu SW, et al. Five-year survivors of brain metastases: A single-institution report of 32 patients. Int J Radiat Oncol Biol Phys 2006;66:801-809.

11. Patchell RA, Tibbs PA, Walsh JW, et al. A randomized trial of surgery in the treatment of single metastases to the brain. [abstract] N Engl $J$ Med 1990;322(8):494.
12. Patchell RA, Tibbs PA, Walsh JW, et al. A randomized trial of surgery in the treatment of single metastases to the brain. $N$ Engl $J$ Med 1990;322:494-500.

13. Bindall RK, Sawaya R, Leavens ME, et al. Surgical treatment of multiple brain metastases.J Neurosurg 1993;79:210-216.

14. Ranasinghe MG, Sheehan JM. Surgical management of brain metastases. Neurosurg Focus 2007;22:E2.

15. Ammirati M, Cobbs CS, Linskey ME, et al. The role of retreatment in the management of recurrent/progressive brain metastases: a systematic review and evidence-based clinical practice guideline. $J$ Neurooncol 2010;96:85-96.

16. Hammoud MA, Ligon BL, Elsouki R, et al. Use of intraoperative ultrasound for localizing tumors and determining the extent of resection: a comparative study with magnetic resonance imaging. J Neurosurg 1996;84:737-741.

17. Solheim $\mathrm{O}$, Selbekk $\mathrm{T}$, Lindseth F. Navigated resection of giant intracranial meningiomas based on intraoperative 3D ultrasound. Acta Neurochir 2009;151:1143-1151.

18. Gerganov VM, Samii A, Akbarian A. Reliability of intraoperative highresolution $2 \mathrm{D}$ ultrasound as an alternative to high-field strength $\mathrm{MR}$ imaging for tumor resection control: a prospective comparative study. J Neurosurg 2009;111:512-519.

19. Tronnier VM, Bonsanto MM, Staubert A, et al. Comparison of intraoperative MR imaging and 3D-navigated ultrasonography in the detection and resection control of lesions. Neurosurg Focus 2001;10:1-5. 